\title{
Dermatology
}

Dermatology 2009;219:84-85

DOI: $\underline{10.1159 / 000209229}$

\section{Follicular Borreliosis: An Atypical Presentation of Erythema Chronicum Migrans}

E. Ducroux ${ }^{\text {a }, ~ S . ~ D e b a r b i e u x ~}{ }^{\text {a }}$, A. Boibieux ${ }^{\text {C }}$, S. Boisset ${ }^{\text {e }}$, C. Roure ${ }^{d}$, S. Dalle ${ }^{\mathrm{a}}$, B. Balme ${ }^{\mathrm{b}}$, L. Thomas ${ }^{\mathrm{a}}$

Departments of a Dermatology and ${ }^{b}$ Dermatopathology, Hôtel-Dieu Hospital, and Departments of ' Infectious Diseases and ${ }^{\mathrm{d} B a c t e r i o l o g y, ~ H o ̂ p i t a l ~ d e ~ l a ~ C r o i x-R o u s s e, ~ L y o n, ~ a n d ~}$ eEast Biology and Pathology Department, Microbiology, Hospices Civils de Lyon, Bron, France

Key Words

Erythema chronicum migrans, atypical $\cdot$ Borreliosis • Perifollicular papules

A 56-year-old woman was referred to our department for an eruption on the front side of the left thigh present for 6 months, accompanied more recently by arthralgia and localized subjective neurological symptoms. The eruption started a few days after an insect bite by a red papule which secondarily enlarged. The erythema was of variable intensity. Clinical examination revealed peripilar red papules of the thigh from the groin to the knee (fig. 1). The patient had no remarkable contralateral keratosis pilaris.

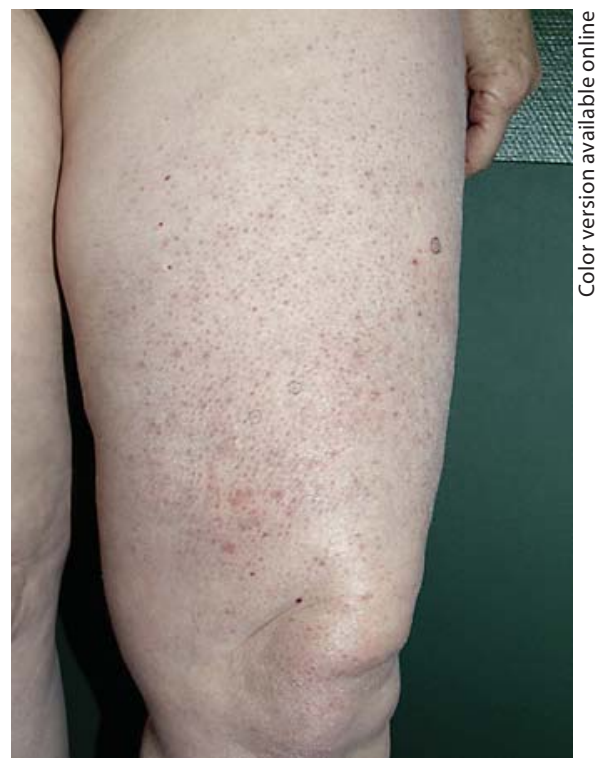

Fig. 1. Erythematous perifollicular papules of the thigh.
Lyme serology was positive for both IgG and IgM (ELISA, Enzygnost Borreliosis ${ }^{\circledR}$, Siemens, Dade Behring, Germany, and blot, Euroline $\mathrm{WB}^{\circledR}{ }^{\circledR}$, Euroimmun, Germany). A punch biopsy of a papule showed a dermal perifollicular (fig. 2) - and occasionnally perineural - infiltrate of lymphocytes and plasma cells, consistent with a borrelial infection. Borrelia burgdorferi DNA was amplified from fresh tissue obtained from a skin biopsy performed on a peripilar papule, using a specific real-time PCR according to Mäkinen et al. [1] (culture not performed). The erythema resolved after a 3-week doxycycline treatment whereas arthralgia and dysesthesia persisted.

Erythema chronicum migrans (ECM) is usually the earliest manifestation of Lyme borreliosis. It occurs a few days, sometimes a few weeks, after the tick bite. Lyme disease is caused by an infection with the spirochete B. burgdorferi, which is transmitted by ixodid ticks. ECM usually begins as a macule or papule at the site of the tick bite and evolves as a centrifugally growing annular erythematous plaque with central clearing. It is usually asymptomatic, but localized pruritus, pain, hyperesthesia or dysesthesia have occasionally been reported [2]. It spontaneously disappears within several weeks, occasionally several months; antibiotherapy shortens the evolution and prevents secondary dissemination which can cause neurological, rheumatological, cardiac, ophthalmological and late cutaneous complications [3]. Posttreatment assessment is clinical [4]. Numerous atypical presentations have been described for ECM: mini erythema migrans [5], erythema with no central clearing, erythema with central induration [6], vesicles [7], ulceration, necrosis or purpura [1], alternating bands of erythema, confluent red or red-blue lesion without central clearing, and even triangular, rectangular or linear lesion $[6,8]$.

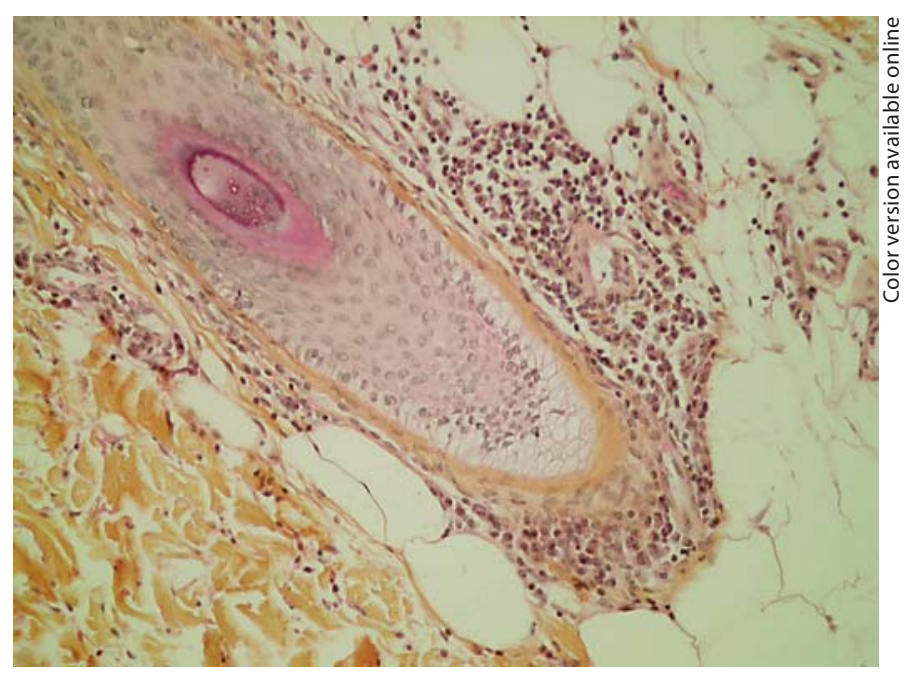

Fig. 2. Lymphoplasmacytic perifollicular infiltrate. $\times 20$.

\section{KARGER}

(C) 2009 S. Karger AG, Basel

Fax +41 613061234 E-Mail karger@karger.ch www.karger.com 
Although diagnosis is usually clinical (serology is often negative at the time of ECM), culture, PCR and histopathology can help to diagnose atypical presentations.

Although the histopathological presentation varies according to the part of the lesion biopsied, skin biopsies typically show superficial and deep angiocentric, neurotropic and eccrinotropic lymphocytic infiltrates, often accompanied by plasma cells and eosinophils, the former at the periphery and the latter in the center of lesions.

The presentation of ECM in our case was both clinically and pathologically original. Such a clinical and histopathological presentation with perifollicular papules due to a perifollicular tropism of the infiltrate has to our knowledge never been described yet.

\section{References}

1 Mäkinen J, He Q, Viljanen MK: Genospecies-specific melting temperature of the recA PCR product for the detection of Borrelia burgdorferi sensu lato and differentiation of Borrelia garinii from Borrelia afzelii and Borrelia burgdorferi sensu stricto; in Reuschl U, Wittwer C, Cockerill F (eds): Rapid Cycle Real-Time PCR: Methods and Applications - Microbiology and Food Analysis. Berlin, Springer, 2002, pp 139-147.
2 Lipsker D, Antoni-Bach N, Hansmann Y, Jaulhac B: Long term prognosis of patients treated for erythema migrans in France. Br J Dermatol 2002;146:872-876

- 3 Aberer E, Kahofer P, Binder B, Kinaciyan T, Schauperl H, Berghold A: Comparison of a two- to three-week regimen and a review of treatment of erythema migrans with phenoxymethylpenicillin. Dermatology 2006;212:160-167.

4 Glatz M, Fingerle V, Wilske B, Ambros-Rudolph C, Kerl H, Müllegger $\mathrm{R}$ : Immunoblot analysis of the seroreactivity to recombinant Borrelia burgdorferi sensu lato antigens, including VIsE, in the long-term course of treated patients with erythema migrans. Dermatology 2008;216:93103.

5 Weber K, Wilske B: Mini erythema migrans - a sign of early Lyme borreliosis. Dermatology 2006;212:113-116.

6 Lipsker D: Dermatological aspects of Lyme borreliosis. Med Mal Infect 2007;37:540-547.

$\longrightarrow 7$ Goldberg NS, Forseter G, Nadelman RB, et al: Vesicular erythema migrans. Arch Dermatol 1992;128:1495-1498.

$\checkmark 8$ Feder HM, Whitaker DL: Misdiagnosis of erythema migrans. Am J Med 1995;99:412-419.

Sébastien Debarbieux

Department of Dermatology, Hôtel-Dieu Hospital

FR-69288 Lyon Cedex 02 (France)

Tel. +33472413060, Fax +33478920939

E-Mail sebastien.debarbieux@chu-lyon.fr 